\title{
SSR markers developed for genetic mapping in flax (Linum usitatissimum L.)
}

\author{
This article was published in the following Dove Press journal: \\ Research and Reports in Biology \\ 2 March 2011 \\ Number of times this article has been viewed
}

\section{Cory L Bickel \\ Sachin Gadani \\ Marshall Lukacs \\ Christopher A Cullis \\ Department of Biology, Case Western Reserve University, Cleveland $\mathrm{OH}$, USA}

Correspondence: Christopher A Cullis Case Western Reserve University, 10900 Euclid Ave, DeGrace Hall Room 203, Cleveland, OH 44I06, USA

Tel +l 2163683557

Fax + I 2163684672

Email cac5@case.edu

\begin{abstract}
Simple sequence repeats (SSRs) are useful molecular markers for genetic mapping and variety identification. A set of SSR markers was developed for use in the construction of a genetic map to identify genes involved in controlling genomic restructuring in flax (Linum usitatissimum L.). SSR sequences were isolated from the flax genome using a modified fast isolation by amplified fragment length polymorphism of sequences containing repeats (FIASCO) procedure. Primers were made around the SSRs, and these regions were amplified using polymerase chain reaction. Forty-two of 92 (46\%) SSRs showed polymorphisms. The number of alleles for each SSR ranged from two to eight, with an average of 3.32. Polymorphism information content (PIC) was calculated for the polymorphic SSRs, with a range of 0.1049-0.8642, the average being 0.47 . Several SSRs were also found informatically using genome sequence data from the flax variety Bethune. Seven of 15 (47\%) were polymorphic, with an average number of alleles of 4.14, and an average PIC of 0.59 . These markers add to the resources available for genetic mapping and variety identification in flax.
\end{abstract}

Keywords: simple sequence repeats, microsatellites, Linum usitatissimum, flax, genetic map, FIASCO

\section{Introduction}

Flax (Linum usitatissimum L.) is a self-pollinating annual crop grown for its fibers and oil. In addition to being important agriculturally, flax undergoes a novel and, so far, unique set of genomic changes in response to nutrient stress that can become stable and heritable. ${ }^{1-8}$ These changes include differences in total nuclear DNA content, copies of large ribosomal ribonucleic acid (rRNA) and 5S rRNA genes, and copies of highly repetitive DNA fractions. ${ }^{6-11}$ Another change is the insertion of a sequence termed Linum Insertion Sequence I (LIS-1), a 5.7 kilobase stretch of DNA, which appears to be assembled from short sequences scattered throughout the genome and is always inserted into the same site..$^{8,12,13}$ The reproducibility of the insertion of LIS-1 and its occurrence during growth make it an excellent marker for classifying a flax genotype as responsive or stable.

To begin to identify the genes controlling these genomic changes, a set of simple sequence repeat (SSR) molecular markers was developed for use in genetic mapping. SSRs, or microsatellites, are tandem repeats of short (2-10 base pair) sequences that often vary in number of repeats, among closely related species and even between varieties within a species, making them useful for genetic mapping. ${ }^{14}$ SSR markers have been previously developed in flax from genomic libraries ${ }^{15-17}$ and from expressed sequence tag (EST) libraries. ${ }^{18}$ Here we report an additional 42 polymorphic SSR 
markers developed from a genomic library enriched for SSRs using a modified fast isolation by amplified fragment length polymorphism of sequences containing repeats (FIASCO) procedure $^{19}$ followed by next-generation sequencing, and seven developed informatically. These markers add to the resources available for genetic mapping and variety identification in flax. In addition, many SSRs were polymorphic between stress-responsive and stable flax lines for which reciprocal crosses and F2 generations are available. These SSRs will be used with the F2 offspring grown under stress conditions to construct a genetic map and identify genes involved in the stress response.

\section{Methods}

\section{Selection of SSRs from genomic DNA (modified FIASCO procedure)}

DNA from the Bison variety of flax, an unresponsive line grown under nonstress conditions, was used for SSR selection. DNA was digested with each of the restriction enzymes HindIII, BamHI (Amersham Life Sciences, Piscataway, NJ, USA), Sau3A (Roche, Indianapolis, IN, USA), HpaII, MspI (New England Biolabs, Ipswich, MA, USA), and Csp6I (Fermentas, Burlington, Ontario, Canada). Digested DNA was cleaned with a Qiaquick polymerase chain reaction (PCR) Purification kit (Quigen, Valencia, CA, USA) according to the manufacturer's instructions, and the purified DNA was dried to a final volume of $20 \mu 1$. Each digested DNA was ligated to one 12-mer and one 24-mer adaptor sequence corresponding to the recognition sequence of the enzyme (Table 1) using T4 DNA ligase (Roche, Branchburg, NJ, USA). The ligation reaction was amplified using the respective 24-mer adaptors as previously described. ${ }^{11}$ PCR products were hybridized with biotinylated oligonucleotides consisting of repeated sequences to capture SSR sequences in the genomic DNA (CA 15, GTT 7, GACA 5, CAC 7, GAG 7, CA 10, AGG 7,

Table I Representational difference analysis adaptors and corresponding restriction enzymes

\begin{tabular}{lll}
\hline Enzyme & \multicolumn{2}{l}{ 24- and I 2-mer adaptors } \\
\hline BamHI, & RBam24 & AGC ACT CTC CAG CCT CTC ACC GAG \\
Sau3A & RBamI2 & GAT CCT CGG TGA \\
HindllI & RBgl24 & AGC ACT CTC CAG CCT CTC ACC GCA \\
& RBglI2 & GAT CTG CGG TGA \\
Hpall, & SHpa24 & ACT TCT ACG GCT GAA TTC CGA CAC \\
Mspl & SHpal2 & CGG TGT CGG AAT \\
Csp 6I & RCsp24 & AGC ACT CTC CAG CCT CTC ACC GAG \\
& RCspl2 & TAC TCG GTG AGA \\
\hline
\end{tabular}

CT 10, AAG 7, TCC 7) as previously described. ${ }^{19}$ The products were cleaned using a Qiagen PCR cleanup kit, and sent for 454 sequencing to inqaba biotec (Pretoria, South Africa).

\section{Data analysis and primer design}

The 454 sequencing data were returned as single-read files and as assembled contigs. The single-read files were reassembled using Bioedit software (version 7.0.0). Singleread and contig data were entered into the program Simple Sequence Repeat Identification Tool (SSRIT; http://www. gramene.org/db/markers/ssrtool) to identify SSRs within the sequences. Sequences containing SSRs with five repeats or more were used to design primers using Primer 3 software (http://frodo.wi.mit.edu/primer3/). There were 103 primer pairs designed, manufactured by MWG Biotech (High Point NC, USA).

\section{Informatic SSR selection}

Sequences from clones from the flax variety Stormont Cirrus were aligned with Bethune variety genomic sequence data using BLAST software (http://blast.ncbi.nlm.nih.gov/). Five sequences were found with SSRs that varied in length between the two varieties. In addition, scaffold 218 from the Bethune genome sequence data was analyzed using SSRIT. Ten SSRs were found that contained eight or more tri-nucleotide repeats. Primers were designed using Primer 3 software as described previously and manufactured by MWG Biotech.

\section{PCR}

DNA from 12 flax varieties and seven related Linum species (Table 2), including the stress-responsive line Stormont Cirrus, were amplified using rTaq DNA polymerase (Takara Bio Inc., Otsu, Japan) with the 103 primer pairs designed from FIASCO selection and the 15 primer pairs designed informatically. PCR involved an initial incubation of $95^{\circ} \mathrm{C}$ for 1 minute, followed by 35 cycles of $94^{\circ} \mathrm{C}$ for 30 seconds, $55^{\circ} \mathrm{C}$ for 30 seconds, and $72^{\circ} \mathrm{C}$ for 1 minute, then a final step of $72^{\circ} \mathrm{C}$ for 5 minutes. PCR products were separated on $3 \%(\mathrm{w} / \mathrm{v})$ agarose gels in 0.5 $\mathrm{X}$ TBE $(1 \mathrm{X}$ TBE $=100 \mathrm{mM}$ Tris, $90 \mathrm{mM}$ boric acid, $1 \mathrm{mM}$ ethylenediaminetetraacetic acid, $\mathrm{pH} 8.4$ ).

\section{PIC value and allele number}

PIC values were calculated using the standard formula: ${ }^{20}$

$$
\mathrm{PIC}_{i}=1-\sum_{j=1}^{k} \mathrm{P}_{i j}{ }^{2}
$$


Table 2 Flax varieties and species used in polymerase chain reaction

\begin{tabular}{ll}
\hline Variety & Origin \\
\hline Stormont Cirrus & From A. Durrant \\
Stormont Motley & USDA \\
CDC Bethune & University of Saskatoon \\
CII303 & C Dean Dybing, North Dakota \\
Koto & USDA \\
AB & USDA \\
Bolley Golden Sel & USDA \\
Burke & USDA \\
Lira Prince & USDA \\
Hollandia & USDA \\
Rembrandt & USDA \\
Royal & USDA \\
L. grandiflorum & Portugal \\
L. strictum & Portugal \\
L. perenne & Aachen \\
L. narbonense & Chelsea \\
L. grandiflorum coeruleum & Romania \\
L. bienne & Aachen \\
L. austriacum & Romania
\end{tabular}

Abbreviation: USDA, US Department of Agriculture

where $\mathrm{P}_{i j}$ is the frequency of the $j$ th allele for the $i$ th marker within the set of flax species and varieties tested, and summation extends over $k$ alleles detected for the $i$ th marker.

The number of alleles was determined by counting every size class of bands that amplified across all varieties and species tested for any given marker. ${ }^{18}$

\section{Results}

Sequencing of the selected genomic DNA returned 13,677 reads with a total of 2,440,703 bases. These were assembled into 1503 contigs (containing more than one read) containing 186,197 bases, which constituted $0.027 \%$ of the total flax genome, which is estimated to be $700 \mathrm{Mb} .^{21}$

Analysis of the contigs with SSRIT showed that 245 contigs contained SSRs with five or more repeats. Primer pairs were made from 62 contigs that had enough sequence surrounding the SSR from which to design primers. Single-read sequences were also analyzed with SSRIT, and 41 primer pairs were made from sequences not found in the contigs and containing five or more repeats. Of 103 primer pairs tested, 11 gave no amplification. Of the 92 primer pairs that amplified, 45 were monomorphic in the flax varieties and Linum species that were tested, and five pairs gave patterns of many bands of sizes not consistent with being due to differences in the number of SSR repeats and so were not used as markers in this study. Of the 42 primer pairs (46\%) that were polymorphic, the number of alleles ranged from two to eight, with an average of 3.32. PIC values ranged from 0.1049 to 0.8642 , with an average of 0.47 (Table 3 ).
When comparisons were made using only the 12 flax varieties, the SSRs were less polymorphic. Nine additional primer pairs were monomorphic within the varieties, lowering the percent of polymorphic primers to $36 \%$. The average number of alleles among varieties was 3.09 , and the average PIC was 0.46 .

For the informatically derived SSRs, seven out of 15 (47\%) were polymorphic among varieties and species, the average number of alleles was 4.14 , and the average PIC was 0.5872 . Among varieties only, the same percentage polymorphism (47\%) held, the average number of alleles was 2.86 , and average PIC was 0.5022 .

Polymorphism of SSR sequences fall within the range of those for previously reported genomic and EST derived SSRs. ${ }^{15-18}$ All of these polymorphic SSR sequences were registered in GenBank (www.ncbi.nlm.nih.gov/genbank). Accession numbers are listed in Table 3.

\section{Discussion}

These data add to the growing number of SSR primers available for flax for use in mapping, variety identification, and phylogenetics. Other markers available for flax include RFLPs (restriction fragment length polymorphisms), ${ }^{22}$ RAPDs (random amplified polymorphic DNA), ${ }^{22-26}$ AFLPs, ${ }^{27-30}$ and SSRs. ${ }^{15-18}$

Informatically derived SSRs were more polymorphic than genomic SSRs found using FIASCO, but this is not surprising considering that many of the informatically derived SSRs were chosen because of previously known polymorphisms between two closely related flax varieties. We expected to find a higher PIC in genomic SSRs compared with those from EST libraries ${ }^{18}$ because of the lack of constraint on the number of repeats in noncoding regions of the genome, but this was not the case. The percentage of markers that were polymorphic among flax varieties was lower in genomic SSRs (36\% in genomic, $40 \%$ in EST), and the average PIC was not significantly different between the two sets $(0.46 \pm 0.16$ genomic, $0.35 \pm 0.17$ ESTs, Student's $t$-test, $P>0.1)$. EST values are reported for flax varieties only, so no comparison is possible for values when related Linum species are screened. The PICs of other genomic SSRs reported were $0.601,{ }^{15} 0.33,{ }^{16}$ and $0.542 .{ }^{17}$ These genomic SSRs are a valuable resource because they are dispersed throughout the genome, rather than clustered in gene-dense regions. When used for mapping, the wider distribution of genomic SSRs makes them an ideal complement to the EST SSRs, which have the advantage of directly tagging the genes they reside in. ${ }^{18}$ Together, these resources can generate a map that is spread evenly over the genome, with the relative locations of many genes being tagged. SSRs that 


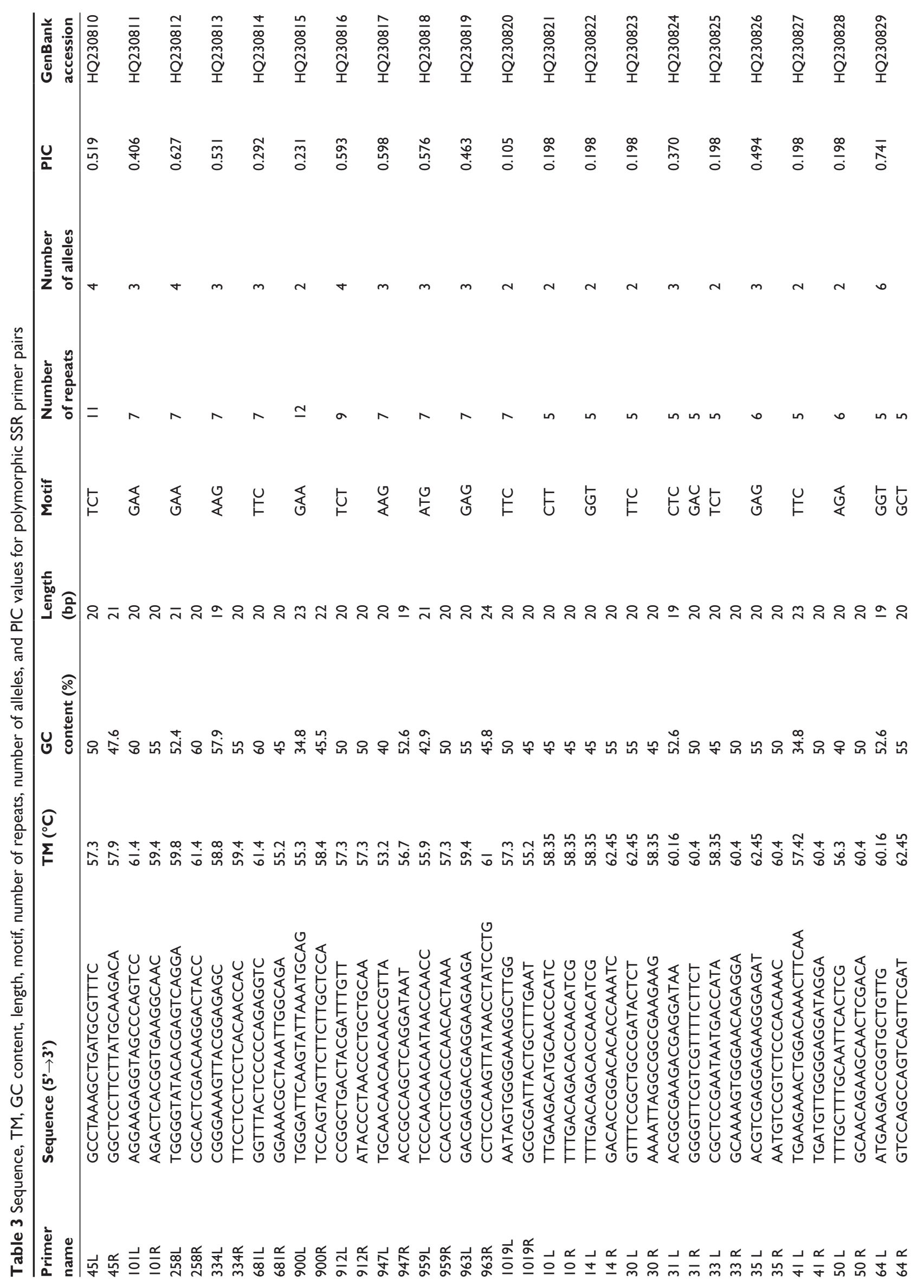




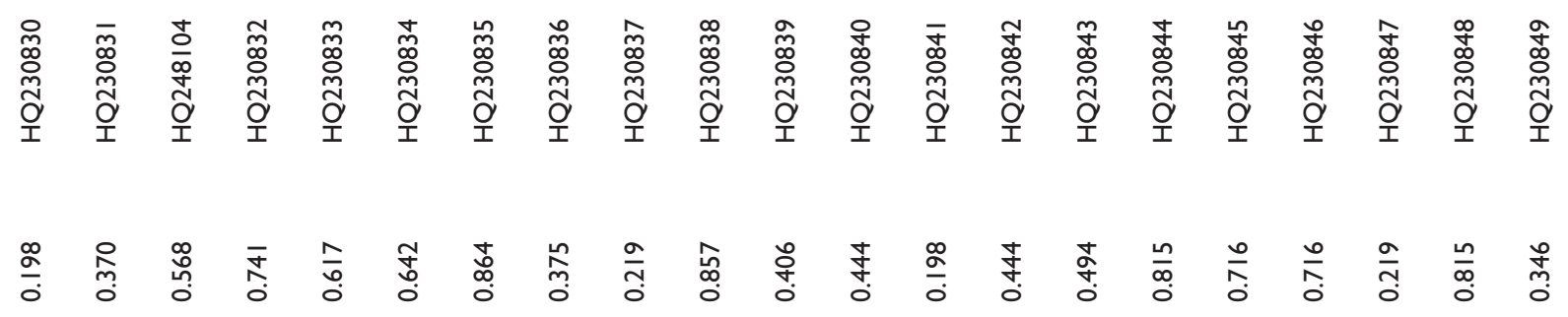

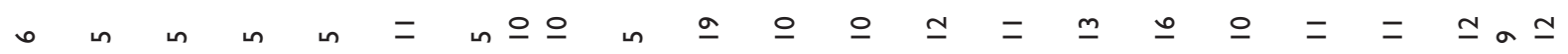

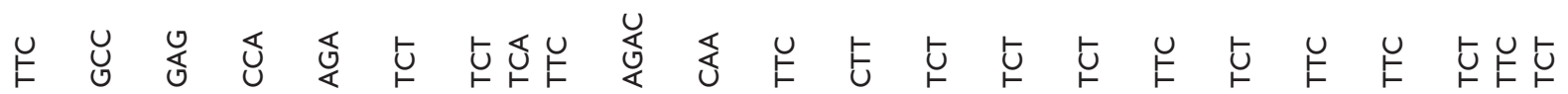

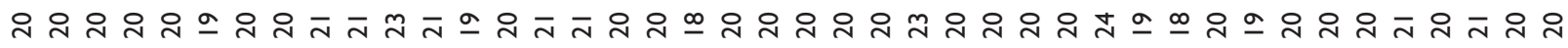

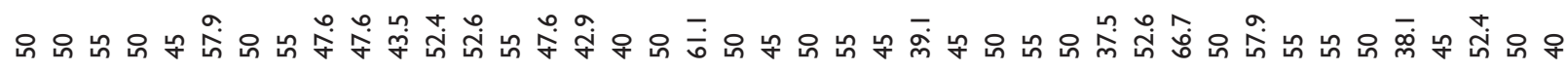

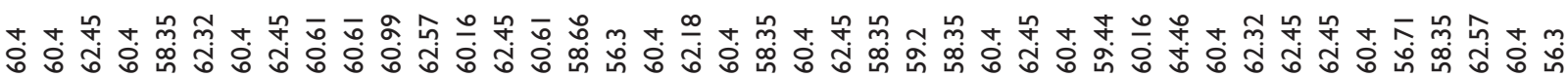

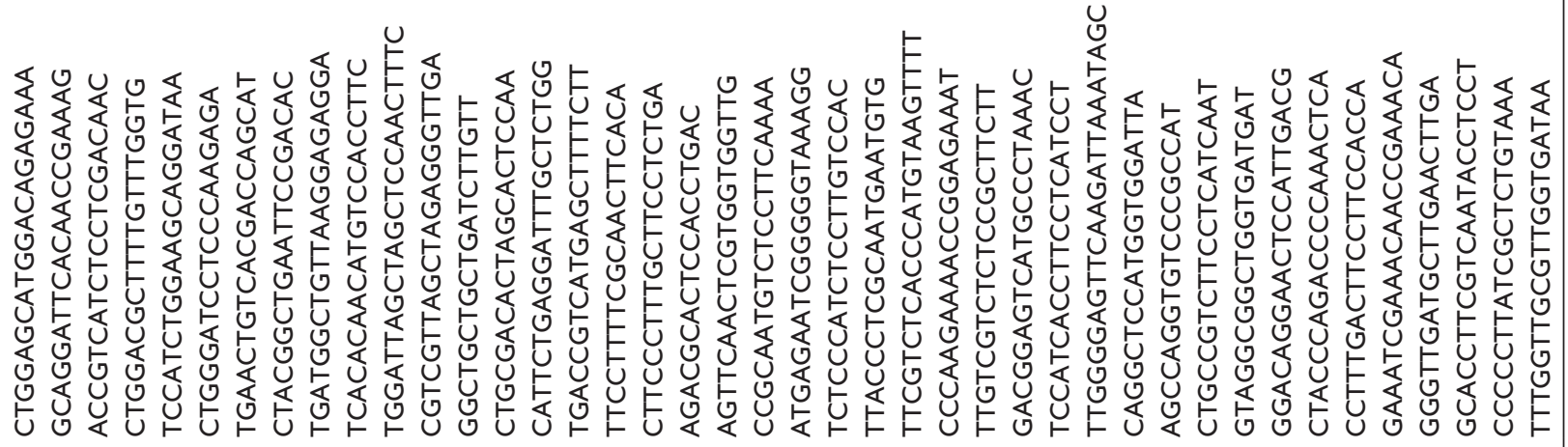

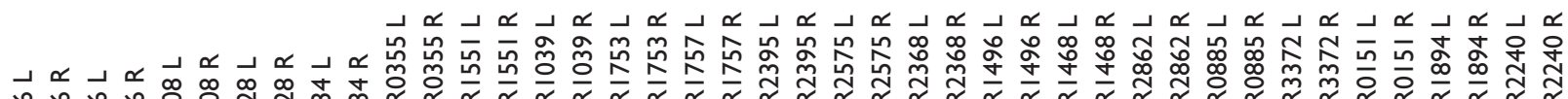

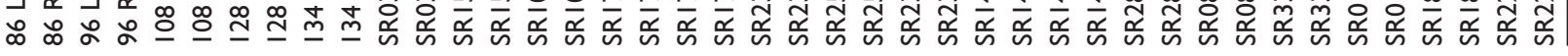




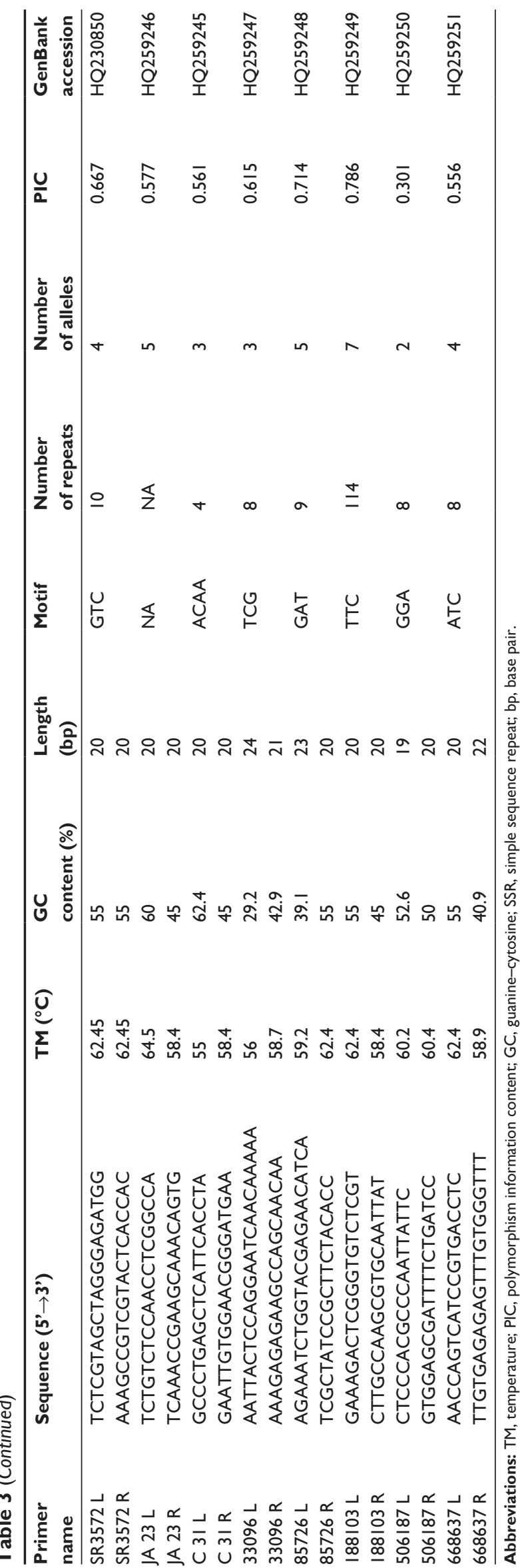

are polymorphic between the cultivars Bethune (a stable cultivar) and Stormont cirrus (a responsive cultivar) will be used to create a genetic map of the flax genome, which will enable the identification of the loci controlling the ability of flax varieties to respond to environmental growth conditions by modifying their genome. ${ }^{8}$

\section{Disclosure}

The authors report no conflicts of interest in this work.

\section{References}

1. Durrant A. The environmental induction of heritable changes in Linum. Heredity. 1962;17:27-61.

2. Durrant A. Induction and growth of flax genotrophs. Heredity. 1971;27:277-298.

3. Evans GM, Durrant A, Rees H. Associated nuclear changes in the induction of flax genotrophs. Nature. 1966;212:697-699.

4. Cullis, CA. DNA differences between flax genotypes. Nature. 1973;243:515-516.

5. Cullis CA. Molecular aspects of the environmental induction of heritable changes in flax. Heredity. 1977;38:129-154.

6. Cullis CA. Environmentally induced DNA changes in plants. Crit Rev Plant Sci. 1983;1:117-129.

7. Cullis CA. Phenotypic consequences of environmentally induced changes in plant DNA. Trends Genet. 1986;2:307-309.

8. Cullis CA. Mechanisms and control of rapid genomic changes in flax. Ann Bot. 2005;95:201-206.

9. Cullis CA, Charlton LM. The induction of ribosomal DNA changes in flax. Plant Sci Lett. 1981;20:213-217.

10. Cullis CA, Cleary W. Rapidly varying DNA sequences in flax. Can J Genet Cytol. 1986;28:252-259.

11. Oh TJ, Cullis CA. Labile DNA sequences in flax identified by combined sample representational difference analysis (csRDA). Plant Mol Biol. 2003;52:527-536

12. Chen Y, Schneeberger RG, Cullis CA. A site-specific insertion sequence in flax genotrophs induced by environment. New Phytol. 2005; 167:171-180.

13. Chen Y, Lowenfeld R, Cullis CA. An environmentally induced adaptive (?) insertion event in flax. Int J Genet Mol Biol. 2009;1:38-47.

14. Powell W, Morgante M, Andre C, et al. The comparison of RFLP, RAPD, AFLP and SSR (microsatellite) markers for germplasm analysis. Mol Breed. 1996;2:225-238.

15. Deng X, Long S, He D, et al. Development and characterization of polymorphic microsatellite markers in Linum usitatissimum. $J$ Plant Res. 2010;123:119-123.

16. Roose-Amsaleg C, Cariou-Pham E, Vautrin D, Tavernier R, Solignac M. Polymorphic microsatellite loci in Linum usitatissimum. Mol Ecol Notes. 2006;6:796-799.

17. Wiesner I, Wiesnerova D, Tejklova E. Effect of anchor and core sequence in microsatellite primers on flax fingerprinting patterns. $J$ Agr Sci. 2001;137:37-44.

18. Cloutier S, Niu Z, Datla R, Duguid S. Development and analysis of EST-SSRs for flax (Linum usitatissimum L.). Theor Appl Genet. 2009;119:53-63.

19. Zane L, Bargelloni L, Patarnello T. Strategies for microsatellite isolation: a review. Mol Ecol. 2002;11:1-16.

20. Anderson JA, Churchill GA, Autrique JE, Tanksley SD, Sorrells ME. Optimizing parental selection for genetic linkage maps. Genome 1993;36:181-186.

21. Bennett MD, Leitch IJ. Nuclear DNA amounts in angiosperms: progress, problems and prospects. Ann Bot. 2005;95:45-90.

22. Oh TJ, Gorman M, Cullis CA. RFLP and RAPD mapping in flax (Linum usitatissimum). Theor Appl Genet. 2000;101:590-593. 
23. Fu Y, Peterson G, Diederichsen A, Richards KW. RAPD analysis of genetic relationships of seven flax species in the genus Linum L. Genet Resour Crop Ev. 2002;49:253-259.

24. Fu Y, Rowland GG, Duguid SD, Richards KW. RAPD analysis of 54 North American flax cultivars. Crop Sci. 2003;43: 1510-1515.

25. Fu YB, Guerin S, Peterson GW, Diederichsen A, Rowland GG, Richards KW. RAPD analysis of genetic variability of regenerated seeds in the Canadian flax cultivar CDC Normandy. Seed Sci Technol. 2003;31:207-211.

26. Stegnii VN, Chudinova YV, Salina EA. RAPD analysis of flax (Linum usitatissimum L.) varieties and hybrids of various productivity. Genetika. 2000;36:1370-1373. Russian.

27. Adugna W, Viljoen CD, Labuschagne MT. Analysis of genetic diversity in linseed using AFLP markers. SINET: Ethiop J Sci. 2005;28:41-50.
28. Adugna W, Labuschagne MT, Viljoen CD. The use of morphological and AFLP markers in diversity analysis of linseed. Biodivers Conserv. 2006;15:3193-3205.

29. Everaert I, Riek JD, de Loose M, van Waes J, van Bockstaele E. Most similar variety grouping for distinctness evaluation of flax and linseed (Linum usitatissimum L.) varieties by means of AFLP and morphological data. Plant Var Seeds. 2001;14:69-87.

30. Spielmeyer W, Green AG, Bittisnich D, Mendham N, Lagudah ES. Identification of quantitative trait loci contributing to Fusarium wilt resistance on an AFLP linkage map of flax (Linum usitatissimum). Theor Appl Genet. 1998;97:633-641.

\section{Publish your work in this journal}

Research and Reports in Biology is an international, peer-reviewed, open access journal publishing original research, reports, editorials, reviews and commentaries on all areas of biology including animal biology, biochemical biology, cell biology, ecological studies, evolutionary biology, molecular biology, plant science and botany.

\section{Dovepress}

The manuscript management system is completely online and includes a very quick and fair peer-review system. Visit http://www.dovepress. com/testimonials.php to read real quotes from published authors.

Submit your manuscript here: http://www.dovepress.com/research-and-reports-in-biology-journal 